\title{
A IMAGEM LATENTE DE SÃO LUÍS: DIÁLOGOS POSSÍVEIS ENTRE A FOTOGRAFIA E A POESIA À LUZ DA MEMÓRIA DA CIDADE
}

\author{
THE LATENT IMAGE OF SÃO LUÍS: POSSIBLE DIALOGUES BETWEEN THE \\ PHOTOGRAPHS AND THE POETRY IN THE LIGHT OF THE MEMORY OF THE CITY
}

\author{
Maria Thereza Gomes de Figueiredo Soares ${ }^{1}$ \\ José Ferreira Junior ${ }^{2}$ \\ Márcia Manir Miguel Feitosa ${ }^{3}$
}

\begin{abstract}
RESUMO: São Luís, palco de significativa produção literária, sobretudo no século XIX, é a cidade natal de Maria Firmina dos Reis, Arthur Azevedo, Aluísio Azevedo, Graça Aranha, Odylo Costa, filho, dentre outros, sendo também o local de nascimento daquele que se destacou na poesia moderna: Ferreira Gullar. A obra gullariana mais emblemática é Poema Sujo, em que traduz, em versos, seu eu-lírico no exílio. Este artigo propõe estabelecer possíveis relações entre a fotografia e a literatura, tendo como eixo de análise a relação da memória com três conjuntos de fotografias da série Visões de um poema sujo, de autoria do artista maranhense Márcio Vasconcelos, inspirada na poesia de Gullar. Considerando a cidade de São Luís como arrimo entre as duas obras, utiliza-se como base teórica o conceito de memória dos autores Michael Pollak e Maurice Halbwachs, com vistas à observação de tais relações. A metodologia empregada é o estudo do caso e o procedimento de análise de dados parte do entendimento desses conceitos de memória, em diálogo com um ponto de vista semiótico na configuração de Charles Sanders Peirce, no intuito de uma leitura da composição imagética enquanto linguagem visual. Como resultado há afastamentos e aproximações entre os dois suportes artísticos (a palavra escrita e a imagem fotográfica), razão pela qual a fotografia pode ser atravessada, por intermédio do olhar fotográfico. Considera-se, portanto, que a imagem propõe ao espectador um jogo de recepção e de tradução, sendo esse um processo no qual são acionados o código verbal (texto de partida) para envolvê-lo no processo tradutório e apontar para o visual (texto de chegada), caminho aberto às subjetividades.
\end{abstract}

Palavras-chave: Poema sujo; fotografia; memória; São Luís.

\begin{abstract}
São Luís, place of significant literary production, especially in the 19th century, is the natal city of Maria Firmina dos Reis, Arthur Azevedo, Aluísio Azevedo, Graça Aranha, Odylo Costa, filho, among others. It is also the birthplace of the one that stood out in modern poetry: Ferreira Gullar. The most emblematic Gullarian work is Poema Sujo, in which he uses verses to translate his poetic persona on the exile. This study proposes to establish potential relationships between photography

\footnotetext{
${ }^{1}$ Doutoranda em Comunicação na Universidade do Estado do Rio de Janeiro-UERJ. Mestra em Cultura e Sociedade-UFMA, Especialista em Artes Visuais: cultura e criação-SENAC, Cineasta-UFF.

${ }^{2}$ Doutor em Comunicação e Semiótica pela PUC-SP. Professor Titular de Jornalismo e dos Programas de PósGraduação em Cultura e Sociedade e em Comunicação Profissional na Universidade Federal do MaranhãoUFMA.

${ }^{3}$ Doutora em Letras-Literatura Portuguesa pela Universidade de São Paulo-USP. Professora Titular de Literatura Portuguesa da Universidade Federal do Maranhão. Bolsista de Produtividade do CNPq- nível 2. Docente dos Programas de Pós-Graduação em Letras e em Cultura e Sociedade
} 
and literature with the analysis based on the relationship between memory and three clusters of photographies from the Visões de um poema sujo series from Márcio Vasconcelos and inspired by Gullar's poetry. Considering São Luís city as the support between these two works, we used the memory concept from Micheal Pollak and Maurice Halbwachs as our theoretical basis. The methodology employed was the case study and the data analysis was based on the understanding of memory concepts in dialog with the semiotics point of view of Charles Sanders Peirce for an imagistic composition as visual language. As a result, there are separations and approximations between the two artistic supports (written word and photographic image), reason which explains how photography can transit through the photographic look. Therefore, we consider that the image proposes a reception and translation game to the spectator, thus being a process in which the verbal code (starting text) to involve it in the translation process, and pointing to the visual (arrival text), an open path to subjectivities.

Keywords: Poema sujo; photography; memory; São Luís.

\section{Introdução}

São Luís, cidade colonizada por portugueses, reconhecida em 1997 pela Unesco como Patrimônio Cultural Mundial, consolidou sua história a partir do seu centro fundacional, conhecido como bairro Praia Grande. O centro histórico da cidade, tombado pelo IPHAN, é formado por ruas e becos de paralelepípedos, solares, moradas com mirantes, sobradões de azulejaria portuguesa e pedras de cantaria advindas do extraordinário terremoto que assolou Lisboa, em 1755, em plena era Pombalina. Aos poucos, a cidade foi crescendo e migrando para os bairros periféricos, tais como Madre Deus, Camboa, Liberdade, entre outros. Apesar de sua geografia insular, em anos idos, cabia ao são-luisense tomar o Caminho Grande para ir à praia do outro lado da ilha, ou seja, percorria um longo caminho por terra partindo do centro em busca do litoral.

A elegia e ideal românticos estão presentes na memória dos que lá habitam. As canções populares da Música Popular Maranhense dão o tom nas vozes do pernambucano Carlinhos Veloz em "Ilha bela", do piauiense César Nascimento em "Ilha magnética" e pela "Louvação à São Luís", do poeta e jornalista maranhense Bandeira Tribuzi (pseudônimo de José Tribuzi Pinheiro Gomes), hino oficial da cidade ("Quero ler nas ruas, fontes, cantarias, torres e mirantes, igrejas e sobrados / nas lentas ladeiras que sobem angústias / sonhos do futuro, glórias do passado"). Somam-se aos versos musicais os resquícios do período da Atenas Maranhense e as alcunhas de "Ilha do amor" e "Jamaica Brasileira". Esses são alguns cenários de histórias e estórias que permeiam o imaginário e a memória do são-luisense.

A identidade maranhense, escrita em verso e prosa por visões particulares de escritores locais como Josué Montello, Gonçalves Dias, Aluísio Azevedo, João Lisboa, dentre outros, ganha diferentes contornos - e é assim que ocorre no aclamado livro Poema sujo, de Ferreira Gullar, em se tratando de um autorretrato descritivo, concebido em seu exílio.

Este artigo pretende abordar como se relacionou a construção imagética de três agrupamentos de fotografias da série de Márcio Vasconcelos, intitulada Visões de um poema sujo, a partir da memória da cidade de São Luís, à luz do livro Poema Sujo, de Ferreira Gullar. O estudo de caso que se segue visa compreender os diálogos possíveis entre a fotografia e a literatura, sob a forma de uma imagem latente, fotografada por Gullar em suas memórias, na tentativa de serem reveladas por Vasconcelos numa elipse temporal cujo cenário é a cidade. A memória, partindo da composição visual do fotógrafo na tentativa de absorver a experiência 
pessoal de Gullar, demanda uma leitura do processo de metalinguagem a partir do qual um olhar semiótico desvela nuances do trabalho literário e artístico.

\section{Visões conceituais sobre Memória}

Os conceitos de memória perpassam vários campos de conhecimentos, sendo, portanto, um fenômeno bastante amplo. De forma breve, esboça-se alguns parâmetros para melhor compreensão do tema proposto, utilizando os teóricos Maurice Halbwachs e Michael Pollak.

A memória é a permanência de parte de informações vividas, que agem no psiquismo e que são cabíveis de reativação. As memórias podem ser individuais - as que se referem à vivência de cada ser, ou coletivas - aquelas que são repassadas de pessoa a pessoa, como, por exemplo, pelos discursos orais de gerações dentro de uma comunidade. Silva e Silva definem que, diferentemente da história oral, a palavra escrita "transforma fundamentalmente a memória coletiva" (SILVA; SILVA, 2006, p. 275), acrescida do respaldo de documento - porém sem desvalorizar a oralidade enquanto instrumento de memória. A memória tem como característica a forma constante de reelaboração dos fatos, assim como o esquecimento também é uma forma de a memória decidir o que deve ser mantido ou não, sendo, portanto, seletiva.

Pollak (1992) nota que a memória, seja pessoal ou coletiva, se faz com os acontecimentos vividos, sozinho ou em grupos. Para este autor, a memória tem variantes para cada pessoa do mesmo grupo, mas pontos de convergência imutáveis. Ao passo que, para Halbwachs, "para confirmar ou recordar uma lembrança, não são necessários testemunhos no sentido literal da palavra, ou seja, indivíduos presentes sob uma forma material e sensivel" (HALBWACHS, 2006, p. 31). Partindo desses pressupostos, busca-se pensar a memória transmutada por Gullar sobre a sua São Luís situada no tempo-espaço da vivência interior do poeta. Poema sujo é um conjunto de imagens textuais da memória individual e coletiva de Gullar, assim refletida por Halbwachs no trecho abaixo:

Não basta que eu tenha assistido ou participado de uma cena em que havia outros espectadores ou atores para que, mais tarde, quando estes a evocarem à minha frente, quando reconstituírem cada pedaço de sua imagem em meu espírito, esta constituição artificial subitamente se anime e assuma figura de coisa viva, e a imagem se transforme em lembrança. (HALBWACHS, 2006, p. 206).

É evidente que a memória coletiva precisa estar em sintonia com as demais, por isso um dado evento tem que estar acordado com as memórias dos outros, legitimando-se desta forma. Vários trechos do poema são evocados em situações em que supostamente havia outras pessoas ou outros registros acerca de, citando diversos personagens reais, como o amigo de infância Esmagado, nomes de ruas, o médico Gonçalves Moreira que tinha canários belgas, entre outros. No contexto da memória coletiva, quando os pensamentos divergem, não são anulados, mas sim entendidos como independentes, compreendidos como pontos de vista singulares.

Pollak, ao complementar a conceituação de memória, afirma que ela precisa de conservação, organização e continuidade. Mesmo que haja divergências advindas do outro, a memória e a identidade não precisam ser reorganizadas em níveis individual e coletivo, pois estão "suficientemente constituídas, suficientemente instituídas, suficientemente amarradas" (POLLAK, 1992, p. 207). 
Com vistas ao entendimento ampliando dos conceitos que norteiam o fenômeno da memória, faz-se necessário adentrar no livro Poema sujo e observar qual o papel da memória na obra e como ela pode ser relacionada à fotografia.

\section{As construções de linguagem na literatura e na fotografia}

François Soulages, acerca da relação possível entre a literatura e a fotografia, afirma que, a princípio, essas duas artes parecem se relacionar em suas essências em três níveis: 1) nível histórico (devido à grande distância temporal que separa ambas, sendo a primeira milenar e a segunda moderna); 2) nível de funcionamento (escrita versus imagem); 3) nível cultural (a literatura é arte consolidada por excelência, nobre, enquanto a fotografia é meramente técnica e mediana). Soulages alega ser difícil a relação entre os dois segmentos e cita como exemplo das experiências de escritores com a fotografia, no que tange ao caráter artístico da fotografia enquanto arte, Baudelaire, crítico da indústria e do realismo imagético advindo da reprodutibilidade da fotografia, entendendo como "[...] inimiga da poesia e do sonho: com ela a técnica substitui a alma do homem" (SOULAGES, 2010, p. 266).

Outro aspecto a ser destacado é o que Soulages aponta como impedimento da criação conjunta que pode resultar da aliança entre fotografia e literatura no que concerne à questão do sentido:

Um jogo dialético senhor/escravo ou senhora/serva vai se desenvolver no início entre literatura e fotografia, com vistas ao reconhecimento da fotografia, quanto à questão do estilo. [...]. Essa evidência do sentido da fotografia faria dela algo ao mesmo tempo original, simples e não artístico, à medida que a polissemia caracteriza a obra de arte. [...]. Mas de fato, diante de toda foto, vários sentidos podem ser produzidos/recebidos em função dela, de seu contexto de apresentação e do receptor. Pode haver unanimidade diante de uma foto, diante de uma imagem. O signo é fechado, a imagem é aberta; o signo é coisa, a imagem é pessoa. É característica da fotografia fato de ser potencialmente rica de um número infinito de sentidos: força explosiva da imagem rebelde (SOULAGES, 2010, p. 267).

O autor também ressalta que essa disputa se torna obsoleta, percebendo que as duas artes podem provocar a transformação uma da outra, deixando para trás questões antiquadas e abrindo-se a novas possibilidades de interação.

Aprofundando mais a questão, Soulages diz que, sem a palavra, a imagem fotográfica nos foge, sendo, portanto, inapreensível. A dupla via é entendida como a legenda que acompanha a imagem, como, por exemplo, a legenda jornalística ou mesmo a palavra seminal que desperta o interesse de materialização de sua percepção pelo ato fotográfico, como cabe na realização de Vasconcelos.

No pequeno texto "Poesia e Fotografia", Sebastião Uchoa Leite faz uma leitura pontual: "Na literatura a influência foi menos marcante, mas visível, tanto na arte narrativa como na poesia. Na poesia moderna, fez-se presente nos processos de revelação da realidade cotidiana" (LEITE, 1998, p. 360).

Em seguida, ao esboçar a relação de influência da fotografia na poesia, Leite revela que 
alguns poetas foram influenciados pela fotografia na tentativa de transmutar a realidade cotidiana.

O autor faz referência aos poetas modernistas, como Carlos Drummond de Andrade, Oswald de Andrade e Mário de Andrade, mas o que chama a atenção é a forte visualidade que algumas poesias imprimem, como o Poema sujo, de Ferreira Gullar. Para Leite (1998, p.360-361): "No poema visual popconcreto de Augusto de Campos, Olho por olho, os elementos fotográficos são índices de um alerta crítico. É, na verdade, poesia conceitual, onde os signos visuais particulares adquirem valor genérico".

Em outra direção, o autor Gabriel Bauret (2015) compreende que a fotografia é uma ferramenta integrante da escrita, mesmo com seu caráter ambíguo e que, sem o uso de textos associados às imagens, não há segurança, porém essa referência se reporta à fotografia documental/jornalista, não configurando o caso da série Visões de um poema sujo.

\title{
4 Poema sujo: a memória de Gullar
}

Ferreira Gullar nasceu em São Luís, em 1930. Convivendo no meio cultural maranhense, ainda cedo despertou o desejo de escrever, mudando-se aos 21 anos para a cidade do Rio de Janeiro, onde teve mais acesso aos círculos literários. Transitou em diversos campos da escrita e das artes, dos quais se destacam os movimentos do Concretismo e o Neoconcretismo, na década de 1950. Participante do Partido Comunista Brasileiro, precisou se exilar durante o regime militar. O poeta se mudou diversas vezes, de país em país, em busca de um lar enquanto a situação brasileira não voltasse a uma condição democrática.

Em plena grave crise governamental pela qual o Brasil atravessa, é pertinente rememorar a música "O bêbado e a equilibrista", de autoria do recém-falecido Aldir Blanc e João Bosco, marcada pela interpretação visceral de Elis Regina (1979), para sublinhar o contexto da ditadura e o destino pelo qual diversos brasileiros optaram no período, em busca de alguma saída para a situação-limite:

\author{
[...] Fazia irreverências mil \\ Pra noite do Brasil \\ Meu Brasil \\ Que sonha com a volta do irmão do Henfil \\ Com tanta gente que partiu \\ Num rabo de foguete \\ Chora \\ A nossa Pátria mãe gentil [...]
}

Gullar descreveu momentos do temeroso período por ele vivido no livro Rabo de foguete: os anos no exílio, no qual inicia o prefácio com as seguintes palavras: "Nunca fez parte dos meus planos escrever sobre os anos de exílio" (2010, p. 5). Ao longo do livro, o escritor narra, desde o momento em que passa a morar clandestinamente na casa da sogra, o desencadeamento progressivo da perseguição política durante o regime militar, os países para onde se mudou, entre outros episódios pessoais.

É dentro de contexto histórico turbulento que surge sua obra mais aclamada, Poema sujo, escrito em 1975, quando exilado em Buenos Aires. A publicação, para Gullar, é um desabafo de 
suas angústias diante da possibilidade de não conseguir retornar à sua terra durante o governo ditatorial. A obra perpassa o universo interior e conflituoso do poeta, que deseja e abandona a rima, usa versos livres, recorre às memórias familiares e infantis, às sinestesias, às onomatopeias e, sobretudo, ao tempo.

Como uma espécie de reconstituição do retrato de sua vida particular, Gullar usou sua cidade natal como pano de fundo, tecendo uma arqueologia imaginária da cidade. Sugere-se que o exercício de elaboração desse poema imprimiu uma busca nas memórias do escritor e das pessoas que lhe eram próximas para, numa tentativa do que Halbwachs cita: "[...] evocar seu próprio passado, em geral a pessoal precisa recorrer às lembranças de outras, e se transporta a pontos de referência que existem fora de si, determinados pela sociedade" (HALBWACHS, 2006, p. 72).

\title{
5 A poesia suja da cidade
}

A partir da observação do poema, é possível notar que a obra de Gullar rompe com o teor nostálgico e de exaltação com os quais outros poetas e escritores maranhenses narravam as suas "Sãos Luíses" e revela um cenário bastante real da cidade, descontruindo arquétipos e apontando dados marginalizados: as zonas de meretrício, as periferias, o abatedouro clandestino, a lascívia, a miséria, os cheiros, em contraponto ao status das classes mais abastadas, as quais também mereceram citações pontuais por parte do poeta. Em um dos versos mais lembrados do poema, o autor "enxerga" São Luís do lado avesso:

\author{
Sobre os jardins da cidade \\ urino pus. Me extravio \\ na Rua da Estrela, escorrego \\ no Beco do Precipício. \\ Me lavo no Ribeirão. \\ Mijo na Fonte do Bispo. \\ Na Rua do Sol me cego, \\ na Rua da Paz me revolto \\ na do Comércio me nego \\ mas na das Hortas floresço; \\ $\mathrm{Na}$ dos Prazeres soluço \\ na da Palma me conheço \\ na do Alecrim me perfumo \\ na da Saúde adoeço \\ na do Desterro me encontro \\ na da Alegria me perco \\ Na Rua do Carmo berro \\ na Rua Direita erro \\ e na da Aurora adormeço \\ (GULLAR, 1983, p. 83-84)
}

É um percurso de ironias, paradoxos, angústias e desgostos. Ferreira Gullar oscila entre a saudade e o desprazer, memórias boas e ruins. Como sugere o próprio poeta, a cidade está nele, mesmo ele estando em outra cidade (GULLAR, 1983, p. 102). Vagueia pelas memórias da infância intrinsecamente afetiva, num misto que o transpõe a uma São Luís de 1975, a qual ele 
não vivenciou presencialmente, apenas afetuosamente - remetendo ao conceito de memória coletiva.

Com viés por vezes denunciatório, Gullar exemplifica por meio de substantivos classificatórios, como mulato, branco, caboclinha, as relações hierárquicas sociais, a exemplo da passagem:

\author{
(a filha do barbeiro fugiu \\ com o filho \\ do carteiro \\ um mulato \\ que trabalhava nos Correios. \\ As vizinhas cochichavam: \\ "se tivesse fugido \\ com um branco \\ ao menos ia poder casar"). \\ (GULLAR, 1983, p. 65)
}

O poeta segue descrevendo como o doutor, que morava na privilegiada avenida BeiraMar, possuía canários belgas em gaiola de prata e que mantinha "[...] uma caboclinha de suas terras de Barra do Corda para arrumar gavetas (lençóis de linho branco cheirando a alfazema)." ${ }^{4}$. Esses paradoxos sociais são elaborados por Vasconcelos pontualmente, não abarcando exatamente todas as indicações contidas no texto original.

A interdisciplinaridade flutua nesta obra gullariana, configurando-se num jogo de figuras imagéticas e/ou sonoras. Numa tentativa de musicalidade, como o próprio autor se propõe a transcrever, buscando novamente em sua memória, ele recorre às onomatopeias enquanto recurso estilístico: "piiuí! piuí piuí [...] tuc tchuc tuc tchuc tuc tchuc [...] IUÍ IUÍ IUÍ IUÍ IUÍ [...] lará lará laraá [...]” . O poeta indica, entre parênteses, ao lado deste verso: "Para ser cantada com a música da Bachiana $n^{\circ} 2$, da Tocata, de Villa Lobos”. Poema sujo não é uma obra que se importa com a rima, e sim com o peso das palavras, e as palavras correm livres, em fluxos. E, nesse fragmento acima, as palavras, talvez, não coubessem. Apenas sons.

No poema, o teor do conteúdo é um fragmento de um tempo vivido pelo poeta exilado, logo entendido como um recorte histórico. Vê-se que a fotografia também é um recorte do tempo e do espaço. O fotógrafo também busca o registro do momento, aquele instante efêmero, que liga o passado (do tempo vivido da imagem) e o presente (do observador ao ver a imagem).

Se na literatura as palavras se transformam em imagens, na fotografia são as imagens que podem gerar palavras. Ambos são textos e são visuais. Visões de um poema sujo é um extenso trabalho de Márcio Vasconcelos, que traduz a busca pessoal de um artista à procura do rastro da memória do outro.

6 Visões de um poema sujo: memória, poema, fotografia e cidade

\footnotetext{
${ }^{4}$ Idem. p. 65.

${ }^{5}$ Idem. p. 31.

${ }^{6}$ Idem. p. 30.
} 
O maranhense Márcio Vasconcelos é autodidata e trabalha com fotografia há, aproximadamente, 30 anos, dedicando-se, sobretudo, à fotografia documental. Em seus principais trabalhos, o destaque se dá para a aproximação da temática cultural local, dedicada às manifestações populares, religiosidades e culturas de matrizes africanas.

A proposta de Vasconcelos ${ }^{7}$ para o desenvolvimento desta série fotográfica surgiu da tentativa de leitura de Gullar sob um ponto de vista particular que lhe fosse próprio, a partir da sua apropriação do olhar sobre São Luís, permeado por memórias próprias da cidade, desde a infância, e pela memória coletiva do são-luisense relacionada à história da cidade. Há de se observar que Vasconcelos se propôs a pensar além da São Luís descrita por Gullar. O fotógrafo, em entrevista, descreveu como se deu seu processo criativo de pesquisa e produção de imagens:

[...] quando o poeta me deu essa autorização, eu caí em campo primeiro não, eu caí na cama, por que eu dormi abraçado com o Poema sujo [...] aí eu "xeroquei" só a parte do Poema sujo e dormia com aquilo na minha cabeceira, e então eu passei mais de um mês lendo sem pegar a máquina fotográfica, mas assim, mergulhando profundamente nesse poema. E aí eu ia com o marcatexto, eu ia grifando fragmentos daquele poema onde eu via uma fotografia [...] esse trecho aqui dá uma fotografia. E depois desse período de mergulho eu parei assim, já tinha mais de 100 fragmentos grifados que dariam fotografias. Aí eu disse: tá na hora de ir pra rua. Tá na hora de ir pra São Luís minha também, por que eu tive a intenção e a liberdade, vamos dizer "poética", de fazer uma visão minha sobre São Luís, eu me colocando também no lugar do poeta até no exílio também, eu me colocando lá em Buenos Aires. Se eu tivesse em Buenos Aires no lugar de Ferreira Gullar, de que maneira eu ia ver São Luís? Porque eu sou profundamente apaixonado por São Luís. Eu tenho uma memória de São Luís muito grande, não fotográfica; uma memória de cabeça mesmo, acumulada na minha cabeça, por exemplo. (VASCONCELOS, p.x.,2016)

Márcio Vasconcelos manteve pouco contato com Ferreira Gullar durante o processo de feitura do seu projeto, obtendo sua autorização para realizar a série. Vasconcelos não conviveu com Gullar, portanto recorreu ao elo da memória coletiva sobre São Luís para pensar suas imagens, visto que são dois artistas são-luisenses, portanto usam de suas memórias enquanto moradores desta cidade, que conhecem o seu clima, seu cheiro, sua rotina, sua geografia, seu universo e sua identidade.

O fotógrafo submerge no universo do escritor que, ao deixar uma pequena porta aberta de sua história, expôs parte de suas lembranças no livro. Compreende-se que, neste caso, é um caminho de mão única: o fotógrafo se ligou às memórias do poeta e relacionou-se às suas próprias percepções, como podemos identificar no pensamento de Halbwachs:

Dois seres podem se sentir estreitamente ligados um ao outro, e terem em comum todos os seus pensamentos. Embora em certos momentos suas vidas decorram em ambientes diferentes, através de cartas, descrições ou por narrativas quando se aproximam, eles podem dar a conhecer um ao outro em detalhes de circunstâncias em que se encontravam quando já não estavam mais em contato (HALBWACHS, 2006, p. 51).

\footnotetext{
${ }^{7}$ Entrevista cedida à jornalista Gisa Franco ao programa Santo de Casa, da Rádio Universidade FM, em 26 de maio de 2015.
} 
O elo que se estabelece entre Vasconcelos e Gullar advém da transcrição de aspectos pontuais de São Luís, descritos, detalhadamente, por Gullar, cedendo uma descrição da paisagem da cidade aos leitores, incluindo o próprio fotógrafo, que nela habita e com a qual tem certa familiaridade.

Já a nova ordem de leitura fotográfica manifestada com as visões atualizadas de Vasconcelos sobre a cidade, ou seja, não mais em 1975, mas em 2015 e 2016, segue um tempo presente em São Luís a partir da vida do fotógrafo e pode ser entendida da seguinte forma, segundo da reflexão de Halbwachs: "É bem verdade que em cada consciência individual as imagens e os pensamentos que resultam dos diversos ambientes que atravessamos se sucedem segundo uma ordem nova e que, neste sentido, cada um de nós tem uma história" (HALBWACHS, 2006, p. 57).

Ressalta-se que Vasconcelos tem acesso às lembranças de Gullar para além do poema, acessando a memória coletiva histórica. Pollak destaca: "É perfeitamente possível que, por meio da socialização política, ou da socialização histórica, ocorra um fenômeno de projeção ou de identificação com determinado passado, tão forte que podemos falar numa memória quase herdada" (POLLAK,1992, p. 201).

Entende-se que este autor propõe uma memória que não é herdada geneticamente, mas como evento registrado em função do momento, portanto histórica. Assim, o poema de Gullar é o mote para a construção imagética de Vasconcelos.

A potência da imagem materializada em fotografia serve de dado concreto da realidade, como instrumento de pesquisa, funcionando como documento passível de apropriações interpretativas individuais com referencial particular, baseado nas memórias coletivas e individuais de cada espectador.

Outra potência da imagem relacionada à feitura de imagens enquanto diferenciador do texto da literatura, como apontada por Kossoy: "No que toca à imagem fotográfica, uma série de dados poderão ser reveladores, posto que jamais mencionados pela linguagem escrita da história" (KOSSOY, 2012, p. 164-165).

Num primeiro momento, as imagens produzidas pelo fotógrafo trazem várias leituras possíveis. Aos são-luisenses, talvez, remetam a um ar de nostalgia ao se depararem com imagens do universo da cidade, de objetos e cenários antigos. Também é possível observar traços identitários, que remetam à memória coletiva sobre a cidade de São Luís: a azulejaria portuguesa, as antigas cadeiras de palhinha, o trilho de um veículo ferroviário que nunca foi concluído, a poeira assentada nas teclas do piano.

Para uma possível assimilação mais ampla dos significados transmitidos por Vasconcelos, não se faz obrigatória a leitura da obra de Gullar, mas certamente o conhecimento prévio da obra e de seu contexto, guiando o entendimento do espectador em relação às imagens propostas. Sobre a familiarização ou não com as imagens, recorre-se ao seguinte trecho do pesquisador Boris Kossoy quanto à relação da feitura de fotografias - de fato, registros visuais com os documentos informativos:

Porém, apesar de ser a fotografia a própria 'memória cristalizada', sua objetividade reside apenas nas aparências. Ocorre que essas imagens pouco ou nada informam ou emocionam àqueles que nada sabem do contexto histórico particular em que tais documentos se originaram. Para estes não há como 
decifrar os conteúdos visuais plenos de incógnitas. Efetivamente, não há como avaliar a importância de tais imagens se não existir o esforço em conhecer e compreender o momento histórico pontilhado de nuanças nebulosas em que as imagens foram geradas. Por outro lado, essas imagens pouco contribuirão para o progresso do conhecimento histórico se delas não se extrair o potencial informativo embutido que as caracteriza. (KOSSOY, 2014, p. 168-169).

O trecho acima denota que se faz necessário compreender o contexto de feitura das imagens. A fotografia já ultrapassou seu status de mera cópia fiel da realidade (o caráter informativo). A busca de significados no ato fotográfico compreende camadas sobrepostas - do mais simples ao mais complexo - como a Semiótica de Charles Sanders Peirce sugere, sobretudo nas construções icônicas, indiciais e simbólicas, presentes na divisão dos signos (PEIRCE, 1987). Portanto, a apreensão absoluta do significado imagético deve levar em consideração camadas de expressão cuja ênfase pode variar, conforme a formulação peirceana.

Para construir uma breve análise em diálogo com os conceitos sobre a memória já elencados, mas agregando-se a semiótica como um farol a iluminar o caminho, incorporam-se exemplos de aplicação da semiótica peirceana, levando-se em conta que há outros caminhos de fundamentação semiótica como o percurso gerativo de sentido da semiótica estruturalista de Algirdas Julius Greimas.

Pela ótica de Charles Peirce, há três pontos de vista: o qualitativo-icônico; o singularindicativo e convencional-simbólico (SANTAELLA, 2005).

Essas serão balizas para nortear a disposição imagética que se seguirá a partir destes arranjos fotográficos do trabalho de Márcio Vasconcelos.

Imagem 1 - Visões de um poema sujo, 2015.

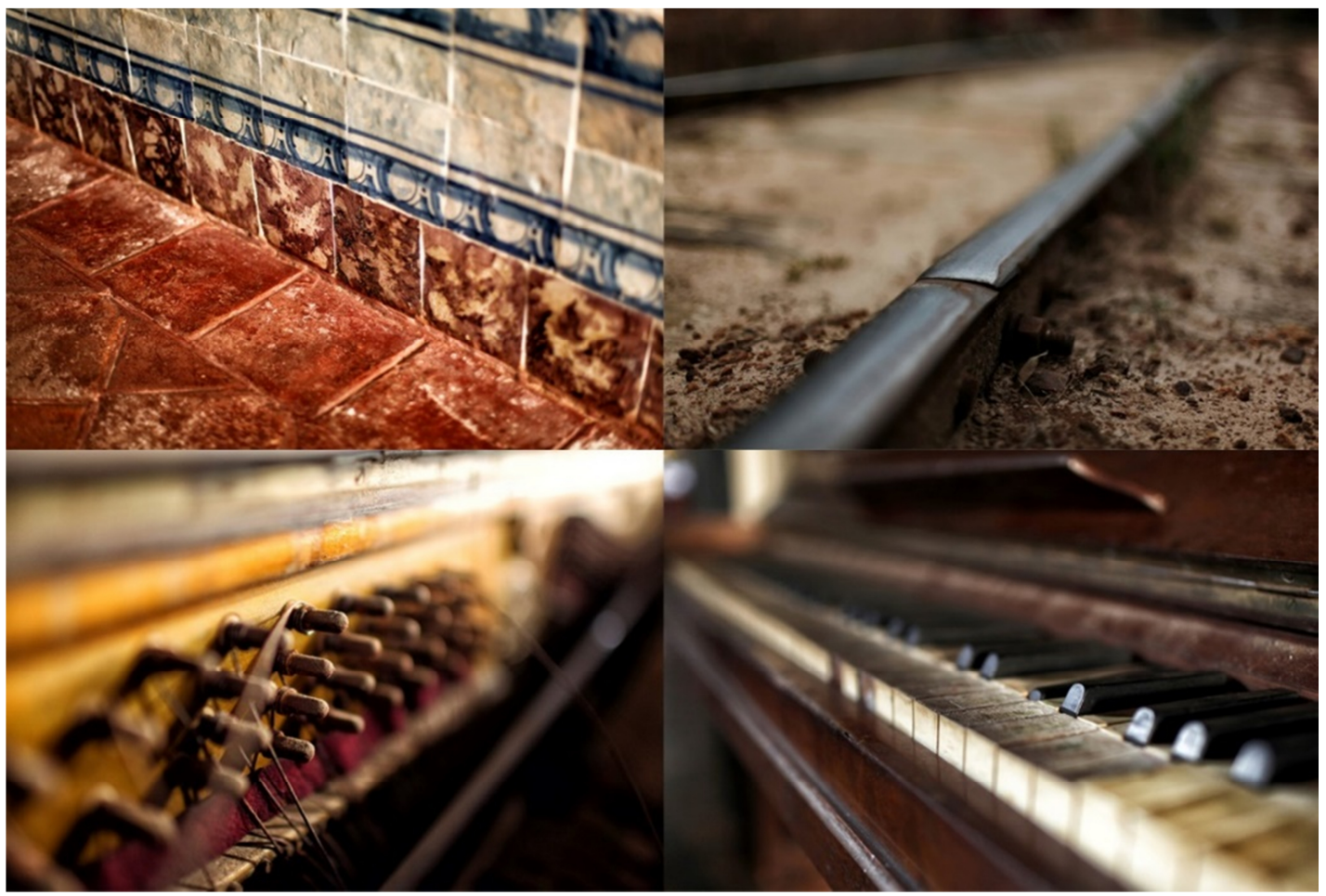

Márcio Vasconcelos. Fonte: cedida pelo autor 
As imagens cedidas pelo fotógrafo em tela estão agrupadas de forma a manterem unidade visual e textual. Portanto, em Imagem 1, observam-se quatro elementos dispostos cujas linhas se iniciam nos cantos da imagem em direção ao centro. São exemplos de forma geométricas, cores e luminosidade, algo que remete ao ponto de vista qualitativo-icônico.

Já na próxima foto, há ponte direta com o texto de Gullar, porque se trata da referência clara ao matadouro - que remete ao tradicional bairro central da Liberdade, onde se situava o abatedouro clandestino que abastecia grande parte da população. Sobre o Matadouro, Gullar situa o local como um novo caminho para que outro rio apodrecesse (ao mencionar o rio Anil) onde hipoteticamente despejaria o cheiro forte e as carniças. Sinestesicamente, a forte sequência de imagem tem impacto pela reverberação abundante do sangue, remetendo as memórias dos espectadores ao cheiro de açougues e feiras.

Imagem 2 - Visões de um poema sujo, 2015

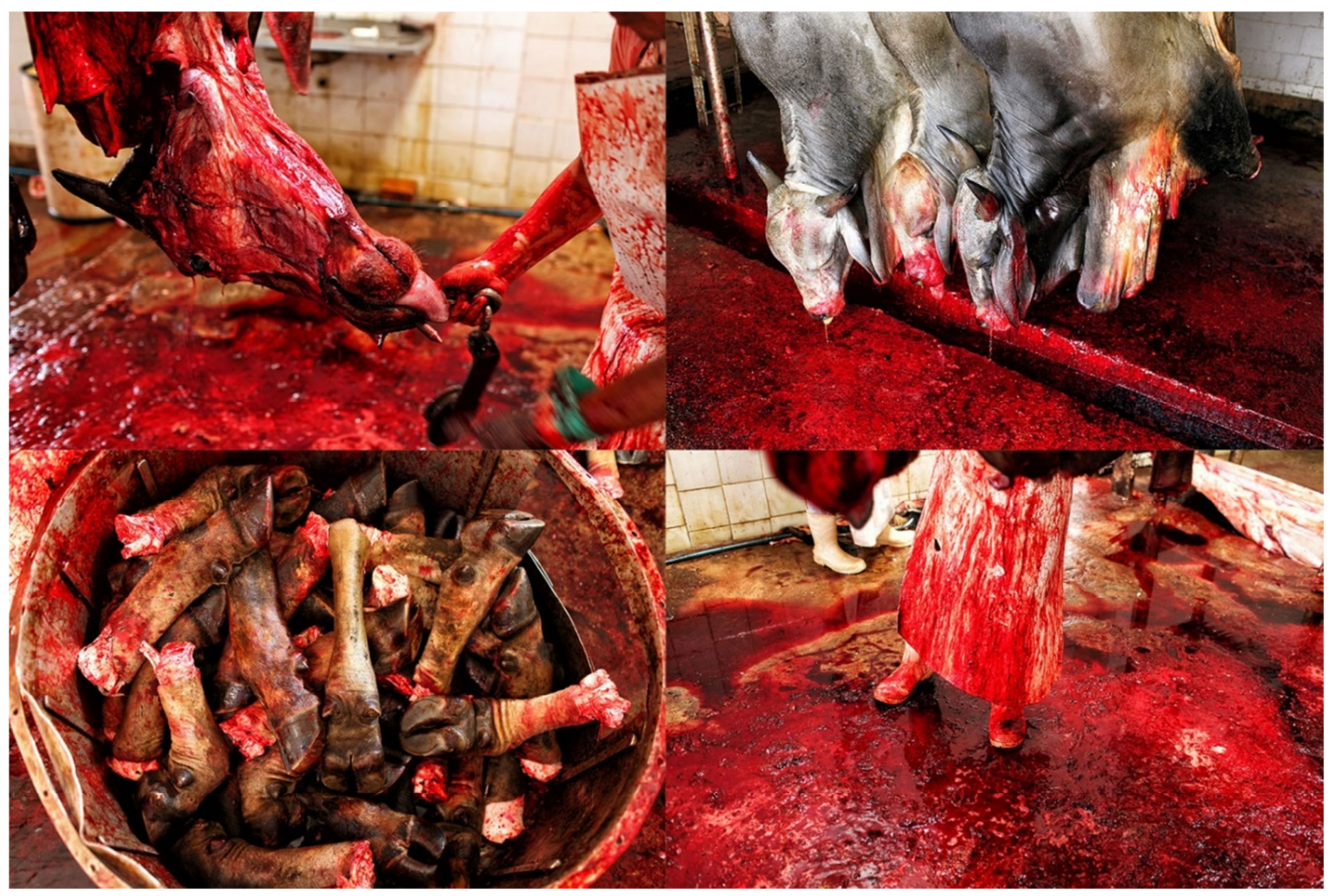

Márcio Vasconcelos. Fonte: cedida pelo autor.

Nessa imagem, observa-se uma sequência de morte. São patas cortadas, sangue derramado, boi com pele e boi escalpelado. A imagem das patas dos animais cortadas está lado a lado com a figura humana, contrastante com as pernas dos homens vivos, responsáveis pelo abatimento. Nela reside um diálogo de vida e morte, porém a predominância do teor remete ao sujo e à morte. Há um recorte na cadeia de abate bovino, não há interesse do fotógrafo em documentar todos os processos de fornecimento deste tipo de carne, selecionando apenas a referência ao abatedouro clandestino, da parte primeira do tratamento do animal já morto na separação das carnes. Traz à tona uma verdade agressiva da procedência da carne consumida por humanos, deixando o expectador vulnerável ao choque que a imagem propõe. Em termos semióticos, tem-se a ênfase do ponto de vista singular-indicativo que se reporta à relação espaço- 
tempo, cujas marcas indiciais estão explicitas em tons vermelho (similitude e indicação) de sangue, mesmo que se trate de uma construção alegórica do fotógrafo.

A fotografia também age no campo do inventário patrimonial particular e íntimo. A partir da observação do retrato fixado na parede na Figura 3, vê-se a foto do registro documental doméstico. Nele, a fotografia aponta para um novo aspecto relacionado à memória: a familiaridade. Nessa imagem paira a nostalgia familiar sob forma de retrato exposto na parede de um local qualquer, cuja tinta está rachada pelo tempo, indicando uma alusão ao passado. Retrato esse com manchas do desgaste temporal, em preto e branco, sugestivo de qualquer casa cuja figura feminina tenha habitado. É a presença da ausência: a pessoa está representada, mas não está lá. Sontag cita:

Uma foto é tanto uma pseudopresença quanto uma prova de ausência. Como o fogo da lareira num quarto, as fotos - sobretudo de pessoas, de paisagens distantes e de cidades remotas, do passado desaparecido - são estímulo para o sonho (SONTAG, 2004, p. 26).

Imagem 3 - Visões de um poema sujo, 2015.

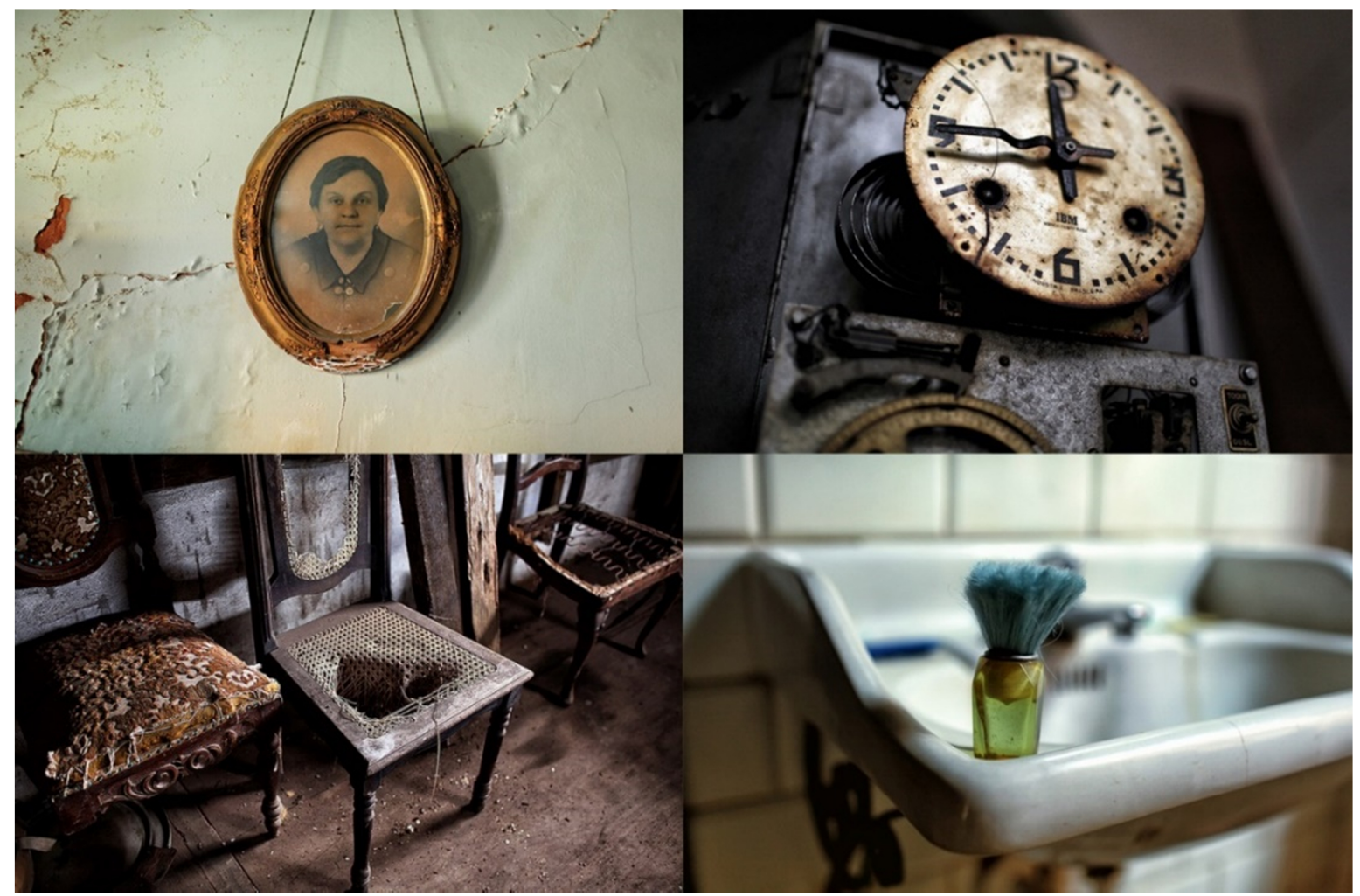

Márcio Vasconcelos. Fonte: cedida pelo autor.

Se, para Sontag, as fotos assumem funções familiarizáveis, como o aconchego de uma lareira no frio, Georges Didi-Huberman (2016) relaciona as imagens com poder de ardência. Se para Gullar era imperativo escrever, para Vasconcelos, era imprescindível acender a luz. Era preciso, para ambos, se movimentar, em urgência. Dito isso, abaliza-se ao que o filósofo francês diz: 
Arde pelo desejo que a anima, pela intencionalidade que a estrutura, pela enunciação, inclusive a urgência que manifesta (como se costuma dizer 'ardo de amor por você' ou 'me consome a impaciência'). Arde pela destruição, pelo incêndio que quase a pulveriza, do qual escapou e cujo arquivo e possível imaginação é, por conseguinte, capaz de oferecer hoje. Arde pelo resplendor, isto é, pela possibilidade visual aberta por sua própria consumação: verdade valiosa, mas passageira, posto que está destinada a apagar-se (como uma vela que nos ilumina, mas que ao arder destrói a si mesma). Arde por seu intempestivo movimento, incapaz como é de deter-se no caminho (como se costuma dizer 'queimar etapas'), capaz como é de bifurcar sempre, de ir bruscamente a outra parte (como se costuma dizer 'queimar a cortesia'; despedir-se à francesa). Arde por sua audácia, quando faz com que todo retrocesso, toda retirada seja impossível (como se costuma dizer 'queimar os navios'). Arde pela dor da qual provém e que procura todo aquele que dedica tempo para que se importe. Finalmente, a imagem arde pela memória, quer dizer que de todo modo arde, quando já não é mais que cinza: uma forma de dizer sua essencial vocação para a sobrevivência, apesar de tudo. (DIDIHUBERMAN, 2016, p. 2016)

A memória remete à ligação qualquer com as imagens presentes neste conjunto: uma vivência com os objetos da rotina íntima familiar. São elementos de diversos períodos, sem precisão de datas, porém reconhecidamente antigos e familiares com características de abandono: cadeiras estragadas, parede descascando, pia de banheiro antiga, relógio de parede enferrujado - parado no tempo. A metalinguagem retrato - retrato ou o relógio "parado" - pode ser entendida como a própria fotografia, que "congela o tempo". A fotografia que se apresenta numa espécie de álbum fotográfico familiar antigo, sempre disposto à leitura, como lembranças do passado materializadas no presente. $\mathrm{O}$ tempo parou e o sentimento de nostalgia contamina os aspectos desse conjunto de imagens. Os elementos encontrados nas fotografias de objetos expostos ao tempo, com a consequente fadiga material, fazem alusão, em termos semióticos, ao ponto de vista convencional-simbólico que trabalha com padrões convencionalmente estipulados, nesse caso o mobiliário e a decoração de um passado distante.

Poema sujo e Visões de um poema sujo são obras distintas, portanto compreende-se que as obras são abertas, independentes, por vezes miméticas (no caso da fotografia em relação ao poema), traduzindo em imagens as passagens poéticas.

Em ruptura com o tom saudosista presente na cultura são-luisense de maneira genérica percebido sobretudo na circulação profícua de imagens antigas da cidade -, Visões de um poema sujo revela uma cidade metaforicamente abandonada, negligente com seu patrimônio - visto o risco da perda de titulação da UNESCO, - pois o que se vê é o lado invisibilizado da cidade. Sontag reforça o caráter nostálgico que a fotografia carrega, inclusive no tempo atual. Por natureza é uma "arte elegíaca”, em que prevalece o caráter honroso do fotografar, mesmo que sejam temas particularmente grotescos, pois a fotografia transforma. Sontag ainda pondera acerca do papel da fotografia sobre esse sentimento: "Além do romantismo (extremado ou não) acerca do passado, a fotografia oferece um romantismo instantâneo sobre o presente (...) o fotógrafo não é simplesmente a pessoa que registra o passado, mas aquela que o inventa" (SONTAG, 2004, p. 82).

\section{Considerações finais}


Poema sujo, obra capital de Ferreira Gullar, cuja primeira edição fora lançada em 1976, é seu desabafo longe de seu país, de forma exasperada, permeada pela constância do medo de ser assassinado pelo regime ditatorial, angústia dos dias e horas do limiar entre esperança de vida e o terror da eminência da morte, do tempo do relógio que parece interrompido, como fotografado por Márcio Vasconcelos.

A cidade que Gullar apresenta no seu vasto poema representa aquela que permeia seus fluxos de memória, entre verdades e ficções, entre o que a memória seletiva optou por manter e a resgatada pela memória coletiva.

As subjetividades e idiossincrasias não são exclusivas do eu-lírico, fazendo parte inclusive do repertório criativo do fotógrafo. Entende-se que para cada artista há suas particularidades. Soulages, comparando pontos de convergência nos processos criativos dos tipos de artista em questão, destaca que "o trabalho do inconsciente é o mesmo no fotógrafo e no escritor: acumulação, deslocamento, metamorfose, sublimação, manifestação, etc” (SOULAGES, 2010, p. 270). Compreende-se que os campos criativos entre poesia e fotografia são semelhantes, com base no argumento do inconsciente.

Walter Benjamin foi o primeiro filósofo que se debruçou sobre das reflexões da fotografia. Georges Didi-Huberman, em seu artigo "Quando as imagens tocam o real", retoma algumas linhas do pensamento Benjaminiano, trazendo, portanto, para a contemporaneidade, refletindo como as imagens se contaminam, atravessam, agenciam pela pujança da ardência, de suas chamas inerentes:

Porque a imagem é outra coisa que um simples corte praticado no mundo dos aspectos visíveis. É uma impressão, um rastro, um traço visual do tempo que quis tocar, mas também de outros tempos suplementares - fatalmente anacrônicos, heterogêneos entre eles - que não pode, como arte da memória, não pode aglutinar. É cinza mesclada de vários braseiros, mais ou menos ardentes. (DIDI-HUBERMAN, p. 216, 2012)

Como numa elipse temporal, há um salto de algumas décadas e contextos sociopolíticos que separam as duas produções apontadas, contudo ligadas fortemente pelo vínculo de identidade e memória maranhenses.

O desabafo dolorido e desanimado do escritor em exílio contorna as ruas de São Luís, numa espécie de álbum fotográfico imaginário, refletindo de certa forma um retrato autobiográfico, imerso em forte teor imagético e críticas sociais, culminando num documento de memórias.

E foram exatos 40 anos para que o papel escrito alcançasse o suporte do papel fotográfico. Pode-se entender como diversos tempos: o tempo da juventude nostálgica do poeta por ele tratada no livro de poesia e o tempo imaginativo dessa memória trazida à baila por Vasconcelos no livro fotográfico. Não se trata de comparações de outrora e a cidade de São Luís do presente, mas de memórias afetivas e subjetivas de cada um dos artistas sobre sua cidade natal. São imagens ardentes na retina de Vasconcelos, desejando materializar-se.

Observa-se que, nas imagens analisadas (com o viés do agenciamento da memória e com classificação semiótica), fruto da realização do fotógrafo, ele enquanto tradutor/autor, estava de fato presente em todos os sujeitos/objetos de cena, por isso compreende-se as imagens 
enquanto fotografia documental. As fotografias possuem vínculos estreitos com a memória, pois assumem para si o papel de registro do real, do tempo congelado, da imagem irreversível, sempre disposta a rememorar o fato, qualquer que seja.

A questão da imagem propõe ao espectador, de forma individual, um jogo de recepção e tradução, sendo esse um processo do código verbal para o visual. Há um texto de partida e um texto de chegada. Um processo de criação artística. Em outras palavras, é a cidade criada pelo texto de Gullar que qualquer um pode conhecer, mesmo que não se conheça São Luís, igualmente para a tradução poético-fotográfica de Vasconcelos.

Halbwachs menciona que a lembrança se encontra num lugar exterior, porventura em espaços diversos. Conclui-se, portanto, que a memória tem papel preponderante nas obras analisadas e que a relação entre literatura e imagem pode ser harmônica, porém a relação direta com a lembrança não é obrigatória. As leituras de imagem são abertas e sua afinidade com a literatura não necessita do viés ilustrativo, ou dos clichês jornalísticos que Didi-Huberman descola do conceito das imagens que tocam o real, permitindo-lhes a liberdade lírica da criação, trazendo as centelhas de Gullar para o braseiro de Vasconcelos, que assopra uma nova fogueira.

\section{Referências}

BAURET, G. A fotografia: história, estilos, tendências, aplicações. 3. ed. Lisboa: Edições 70, 2015.

DIDI-HUBERMAN, G. Quando as imagens tocam o real, Pós, Belo Horizonte v. 2, n. 4, pp. 206-209, nov 2012.

FALCÃO, A. O bêbado e a equilibrista: em 1979, Elis Regina deu voz ao hino da Anistia. Portal EBC, 2016. Disponível em: <https://www.ebc.com.br/cultura/2014/08/o-bebado-e-aequilibrista-em-1979-elis-regina-deu-voz-ao-hino-da-anistia〉. Acesso em 16 maio 2020

GULLAR, F. Poema sujo. Rio de Janeiro: Civilização brasileira, 1983.

GULLAR, F. Rabo de foguete: os anos no exílio. Rio de Janeiro: Revan, 2010.

HALBWACHS, M. A memória coletiva. São Paulo: Centauro, 2006.

KOSSOY, B. Fotografia E⿱ história. São Paulo: Ateliê Editorial, 2014.

PEIRCE, C. S. Semiótica. São Paulo: Perspectiva, 1990

POLLAK, M. Memória e identidade social. Estudos Históricos, Rio de Janeiro, v. 5, n. 10, pp. 200-212, jul./dez. 1992.

PROGRAMA PERFIL. Entrevista: Márcio Vasconcelos (Bloco 01), 13 minutos, 2016. Disponível em: <https://www.youtube.com/watch?v=-1ZhNZMpnTs >. Acesso em 13 set 2016.

REGINA, E. O bêbado e a equilibrista. Elis, essa mulher. 1979. Disponível em: <http://www.elisregina.com.br/Por-Elis/Albuns/>. Acesso em 16 maio 2020

SANTAELlA, L. Semiótica aplicada. São Paulo: Pioneira Thomson Learning, 2005.

SILVA, K. V.; SILVA, M. H. Dicionário de conceitos históricos. São Paulo: Contexto, 2006.

SONTAG, S. Sobre fotografia. São Paulo: Companhia das Letras, 2004. 
SOULAGES, F. Estética da fotografia: perda e permanência. São Paulo: Editora Senac São Paulo, 2010.

UCHOA LEITE, S. Poesia e fotografia. In: TURAZZI, M. I. Fotografia. Revista do Patrimônio Histórico e Artístico Nacional. Brasília: Instituto do Patrimônio Histórico e Artístico Nacional, n. 27, 1998, pp-360-361.

VASCONCELOS, M. Entrevista Visões de um poema sujo. [mensagem pessoal] Mensagem recebida por<therezasoares@gmail.com> em 14 set 2016. Entrevista cedida a Maria Thereza Soares

VASCONCELOS, M. Entrevista: Márcio Vasconcelos (Bloco 02), 12 minutos, 2016. Disponível em: <https://www.youtube.com/https://www.youtube.com/watch?v=tsWex69yRR0 >. Acesso em 13 set 2016

VASCONCELOS, M. Entrevista: Márcio Vasconcelos (Bloco 03), 20 minutos, 2016. Disponível em: 〈https://www.youtube.com/watch?v=mOFjWzP9N58>. Acesso em 13 set 2016

VASCONCELOS, M. Visões de um poema sujo. São Paulo: Vento Leste, 2016.

Recebido em: 17/05/2020

Aceito em: 23/06/2020 